\title{
Celebrating 25 years of seismology at schools in France
}

\author{
Jean-Luc Berenguer ${ }^{1}$, Julien Balestra ${ }^{1}$, Fabrice Jouffray ${ }^{1}$, Fabrice Mourau ${ }^{2}$, Françoise Courboulex ${ }^{1}$, and \\ Jean Virieux ${ }^{3}$ \\ ${ }^{1}$ Géoazur, Universite Côte d'Azur, Observatoire Côte d'Azur, CNRS, IRD, Valbonne, France \\ ${ }^{2}$ Pierre de Coubertin Middle School, Le Luc, France \\ ${ }^{3}$ CNRS, IRD, IFSTTAR, ISTerre, Université Grenoble Alpes, Grenoble, France
}

Correspondence: Jean-Luc Berenguer (jean-luc.berenguer@univ-cotedazur.fr)

Received: 7 July 2020 - Discussion started: 20 August 2020

Revised: 30 October 2020 - Accepted: 2 November 2020 - Published: 23 December 2020

Abstract. An educational program focusing on seismological activities for school and university students that trains in observational sciences and raises citizen awareness of natural hazards has been active in France since 1995. Over this quarter century, different generations of students have learned various lessons concerning instrument installation, data recording, and analysis. These actions have led them into the field of scientific interrogation and interpretation, making them better prepared for our modern technological societies. We describe these student commitments that have been motivated by the installation of the first educational broadband seismometer in southern France. Analysis of regional earthquakes has generated a greater awareness of the seismic hazards where students live, while records of strong earthquakes all around the world have led to interaction between students, especially after the deployment of additional seismometers in schools. The natural extension of such an educational seismic network, first at the national level in France in 2006 and later in many countries through various collaborations, has enriched the pedagogical practices of teachers, increasing their skills in seismology and natural sciences among various other disciplines and complementing standard educational resources. We describe the necessary and sustainable relations between teachers and researchers over time. Combining students' motivation, teachers' experience and researchers' expertise has led to different hosting structures over the years. We conclude by presenting the feedback from a survey carried out in 2019 among all the teachers involved, highlighting the strong and weak points of such a long-term adventure. Recent integration into the official syllabus of the new Geosciences high school curricula in
France illustrates the impact of such an exceptional experience.

\section{Introduction}

Earthquakes occur suddenly and cause severe damage to the infrastructures of our modern societies, leading to high numbers of casualties. These events are unavoidable, but their impact can be significantly mitigated. They remain unpredictable even with our current scientific knowledge. Moreover, although they are both worrying and fascinating to us.

This is why emphasis must be placed on awareness, especially in the school system where the causes and effects of these hazards are studied. The idea of an educational seismic network arose in the United States with the Princeton Earth Physics Project (PEPP) proposed by Nolet and Phinney in 1993 (Steinberg et al., 2000). Pursuing the same objective, an educational seismic network was initiated in France in 1995 and is still active after 25 years.

Today, many other educational seismic networks exist around the world, including the United States, Great Britain, Greece, Portugal, Australia, Nepal, Taiwan, Haiti, and more, providing an indication of the importance of and need for distributing seismic sensors to schools for educational purposes. The installation of seismometers at schools promotes learning based on original records. Such learning makes students familiar with scientific data. With acquired experience, students can download other data from environmental agencies for their own investigations. The program also allows for collaboration between teachers and researchers in order to better collect and analyze the seismic data. Such interac- 
tions allow teachers to develop teaching materials for their classes. Moreover, this teaching material is provided on a website to other educators within the same discipline. It has been observed that these online resources have been used by a broader community of teachers in many fields, including natural sciences, history, geography, and social sciences.

Through this unique, long-term experience, this paper contributes to answering the following questions: how and why has the French educational system evolved over time and benefited from the deployment of a dedicated seismic network? Why is collecting scientific data inside a school important for both teachers and students? How have motivated teachers been able to expand online educational exercises to studying their own data and the data that has become increasingly available on the web? How have such original educational resources been shared with other teachers across school and national boundaries? What skills and support are needed to maintain an active educational network? Why can we not rely only on the open data sets available on the web? How has such an experience impacted French teaching programs?

\section{Sismo des écoles: the first French school network}

In 1995, thanks to the PEPP initiative, the design of a dedicated educational seismometer began in France, including a broadband three-component velocimeter associated with a 24-bit high dynamic digitizer synchronized by GPS with a precision of $1 \mathrm{~ms}$ (Fig. 1a). It was installed at the International Campus of Valbonne (CIV; pilot school). This sensor and its control card were monitored via a personal computer and a telephone line. In order to share scientific information between schools, the automatic nightly gathering of time-windowed records of local, regional, and long-distance events, when strong enough, was generated from the earthquake catalogs of international agencies. At that time, seismic sensors and related seismograms were more or less an abstraction for the school community. The first active group of 12 high school students was created, meeting weekly to share the analyses of seismograms from the station and related information collected through newspapers. This very committed group was supervised by a teacher who interacted closely researcher, and both were involved in this prototype project at the CIV. For the very first time, students had immediate access to global earthquake seismicity from the seismometer within their school. The seismometer and its records provided some concrete aspects to virtual questions related to seismic hazards and to the knowledge of the Earth's structure, which are key scientific topics for French high school education. Students and teachers tracked seismic events, such as the Chi-Chi earthquake (Fig. 1b), and other natural or anthropogenic vibrations (sea swell, human activity, quarry blasts, etc.).
In 1996, the French Ministry of Education decided to connect all the schools to the internet for student training. However, these institutions were very concerned about the added pedagogical value of using the internet in schools. The seismic network thus benefited from this advancement in connectivity; the prototype seismometer was connected to the network. The first online educational seismic database was born. Teachers in other schools were able to work on the online seismic data sets. At the same time, regional political concerns focused on the education of young people about natural hazard awareness in one of the most active seismic zones in France. The prototype station demonstrated that an in-school seismic network to promote educational program was possible. A first financial grant was given to the Alpes Maritimes region. A network of five schools equipped with three-component broadband sensors was set up in the south of France (regional deployment in Fig. 1c; Virieux et al., 2000) and proved to be so successful that the extension to a national configuration was proposed. The organization of such a network was based on voluntary proposals from a team of teachers. The equipment was provided free of charge, while maintenance was the responsibility of the volunteer school.

\section{An increasing network of teachers specializing in seismology}

This network, which is constantly increasing, has been supported by different regional and national funds. In 2006, the French national Sciences à l'École organization integrated the existing Sismo des écoles network into their national educational projects. This cooperation enabled the transformation of local actions into widespread initiatives. The network, renamed SISMOS à l'École, was first deployed on a national level, followed by international deployment in French schools abroad, as illustrated in Figure 1c. This figure shows the role of the professional and educational sensors. (See the data availability section at the end of the paper for further details.) In order to fulfill the educational target of seismic hazard education and scientific approaches, having teachers who are well trained in seismological skills as an interface between teachers and researchers is mandatory and requires specific workshops. Each school with an installed sensor has an identified researcher (one teacher is paired with one researcher who acts as a mentor). Researchers have comprehensive knowledge of seismic phenomena and teachers have the pedagogical skills to describe these phenomena to students. Researchers have also contributed to the numerous training sessions through scientific refresher lectures. Furthermore, the researchers also use the network's data sets to integrate them into the seismicity study of the considered areas (Berenguer et al., 2013; their Fig. 6). 
(a)

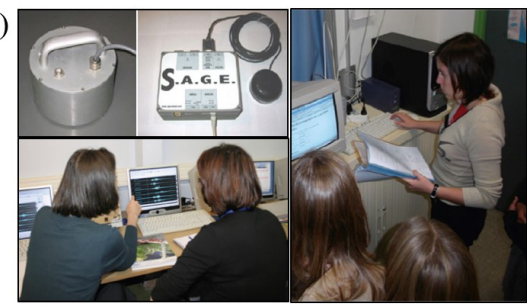

(b)

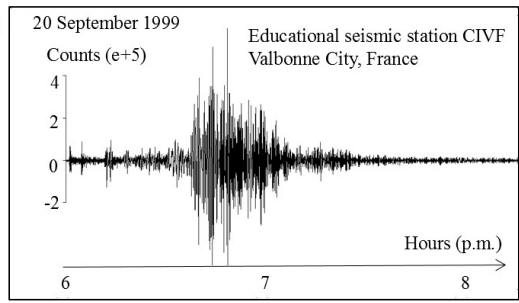

(c) Cumulated total number of deployed seismometers

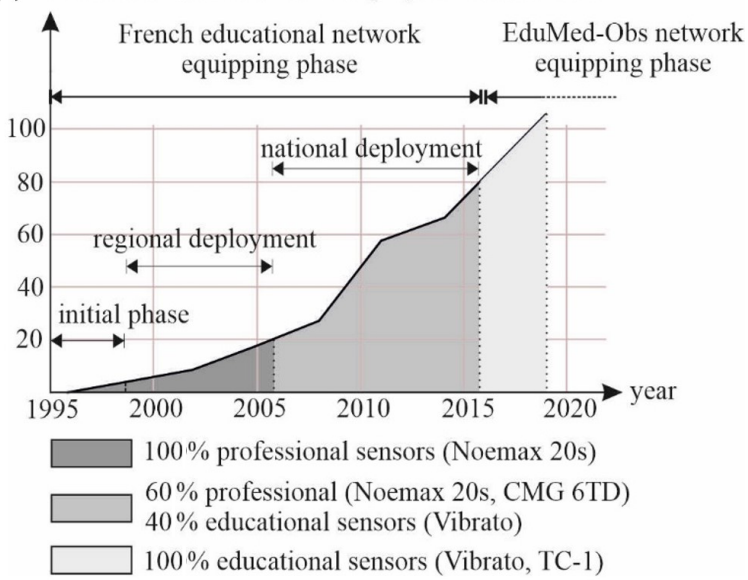

Figure 1. First educational seismic stations deployed at the International Campus of Valbonne (CIV). (a) Students working on seismograms from a specific educational database. Informed consent was provided by the individuals pictured for the publication of these identifiable images. (b) Record of the Chi-Chi earthquake (Taiwan, $M_{\mathrm{W}}$ 7.6), which occurred on 20 September 1999 and was recorded at the French educational CIVF seismic station. Values in abscissa are the after-noon hours of the current day (universal coordinated time - UTC). (c) Evolution of the number of educational seismometers deployed during from the past (equipping phase of the French educational network) to the present with the EduMed-Obs project. Colors under the curve and corresponding colored boxes give an indication of the kind of sensors deployed during each phase. (See the data availability section at the end of the paper for further details.)

\subsection{Regional, national, and international teachers' workshops}

In the last 25 years, different meetings have been offered to any teacher who wanted to increase their own skills in seismological topics. In order to maintain significant momentum within the national (and overseas) network, six national meetings have been held since the beginning of the project, with a total of 200 teachers attending at least one of the proposed meetings. These ongoing training sessions thus keep the educational network alive. Topics are related to following items:

- scientific conferences presented by scientists and specialized teachers,

- practical workshops around data sets from the network, and

- poster presentations to share experiences in different schools.

This format was finally recognized as very useful and helpful for the optimal use of scientific data sets through the interaction of researchers participating in these teachers' workshops and with the participation of the young students whose awareness has been raised. At a different scale, European teachers' workshops were organized under the umbrella of European research projects, such as the NERA, O3E, and SERA projects (see the Acknowledgements). These workshops, supported financially by European projects, have provided the opportunity to mix the different cultural styles of educational training that one can find among the different European countries.

\subsection{A long-standing production of teaching resources}

At the early stage of the network, the teachers shared their pedagogical experiences of exploiting in-school seismometers and available data sets on the web. Initial activities focused on the interpretation of dates, travel times, and the recognition of seismic waves. With the accumulation of new data combined with their increasing seismological skills, teachers started to produce better-developed activities focusing on different and more complex aspects. The development of digital tools at schools has enabled the development of original activities to manipulate numerical quantities. For example, by combining information from seismic catalogs and spreadsheet tools, students are able to display coordinates of listed seismic events on a map and observe that the distribution of each plot enables them to highlight areas which look like tectonic plates. Manipulating these catalogs by themselves enhances their understanding of where and how the information is obtained, which is an added value with respect to push-button applications. An extensive collection of different shared activities was undertaken and finalized through an exercise book Le cahier d'activités du SISMO (The seismo hands-on book; Berenguer et al., 2009; Fig. 2a; see the data availability section at the end of the paper for further details). This collection is an illustration of what can be done with the help of seismic data collected in schools. Quite sophisticated scientific topics may be tackled in a simple and pragmatic way during teaching and training. We can cite an example 
of a practical activity that has become very popular in the classroom. The experiment consists of causing the rupture of a rigid material (polystyrene, uncooked lasagna sheets, hard chocolate, etc.) and recording, with the help of simple piezoelectric cells, the waves that propagate around the rupture (Le cahier d'activités du SISMOS, pp. 24-25). More activities are available in the digital version available online (see the data availability section at the end of the paper for further details).

\subsection{Successive web platforms to improve sharing}

All records and activities have also centralized on successive dedicated web platforms for open sharing. At the outset of the project, a web server was hosted by the regional services of the French Ministry of Education. Thus, the records from regional and global seismic activity feed an online database and constitute a seismic resource center for education. Teaching requires a didactic approach to resources. The need for a more sophisticated platform emerged; this is why the web interface of our educational program goes beyond a simple data center. In 2010, the Edusismo website (http://www.edusismo.org/, last access: 30 October 2020) was developed through funds provided by the French ministerial "Sciences à l'École" program. This website was a cornerstone for providing tools (experiments, software, and simulation) to properly exploit the available data sets and many different educational paths to learning. The two first main digital tools used were as follows:

- SeisGram2K (Lomax, 2000; see the data availability section) software, an interface for the seismological research community and adapted for schools. Students can display seismograms, apply filtering processes, pick wave arrival times, and more.

- EduCarte geographical information software (see the data availability section) which enables users to plot geo-referenced information, work with seismograms, display GPS measurements, create cross sections, and more.

Making these data sets didactic through simple and welldeveloped steps remains the priority of our program.

to recharge my batteries

\section{New impetus for natural risk prevention with the EduMed Observatory}

In 2017, the University of Côte d'Azur took over with a program called Educational Mediterranean Observatory (shortened to EduMed-Obs; http://edumed.unice.fr, last access: 6 December 2020). EduMed-Obs focuses on implementing an interface based on a geoscience data set concerning the Mediterranean basin. The theme does not only focus on seismology; landslides, meteorology, hydrology, and sea-level variations are also considered. Data mining is developing and has become more important in current teaching programs (Bigot-Cormier and Berenguer, 2017). These data sets are intended not only for middle and high schools but also for university students. EduMed-Obs also provides data sets from research centers. This aspect is important for strengthening the visibility of the activities of research institutes. It is an excellent opportunity for students to compare data sets from their own sensors with research data sets. Making communities aware, through student training, of the role of Earth science observatories is crucial and promotes a better understanding of the seismological (and environmental) nature of the territory in which students live. How these observatories participate in our seismic risk awareness is also better understood by governmental structures, leading to improved territorial management such as tsunami mitigation. This new educational observatory already includes some 70 European schools in the countries around the Mediterranean that host sensors and which implement scientific teaching focused on natural risk education (schools map available at http://edumed.unice.fr/fr/le-reseau-edumed, last access: 6 December 2020). The schools that are twinned within this network can share their experiences of natural risks along the Mediterranean coast. EduMed-Obs is a partner of many innovative field camp training courses organized around the Mediterranean, like "InsegnaciEtna 2019" in Sicily (http://site.ietna.eu/, last access: 6 December 2020). This expertise is already being exported through initiatives in central America, where a network is being built on the Caribbean arc from Haiti to Venezuela via the French West Indies (http://edumed.unice.fr/fr/eduseis, last access: 6 December 2020). The recent creation of EduMed-Obs and its present and future actions are directly inspired by the feedback from the teachers involved in this project over the past 25 years. Below, we propose a description of the key points mentioned by the teachers over the years.

\section{A look at the past actions of the French educational seismological network}

Teachers have reported a number of positive points from their experience, including the students' enthusiasm for recording quakes, the ease of understanding online databases, the development of autonomy, students' responsibility in managing a seismological station, and the importance of natural risks within the theme of sustainable development. One of the great strengths of the network has been its integration into teaching programs, and it has fulfilled various expected educational objectives, such as the following:

- practice a scientific approach,

- demonstrate observation skills, curiosity, critical thinking,

- experience autonomy, and 


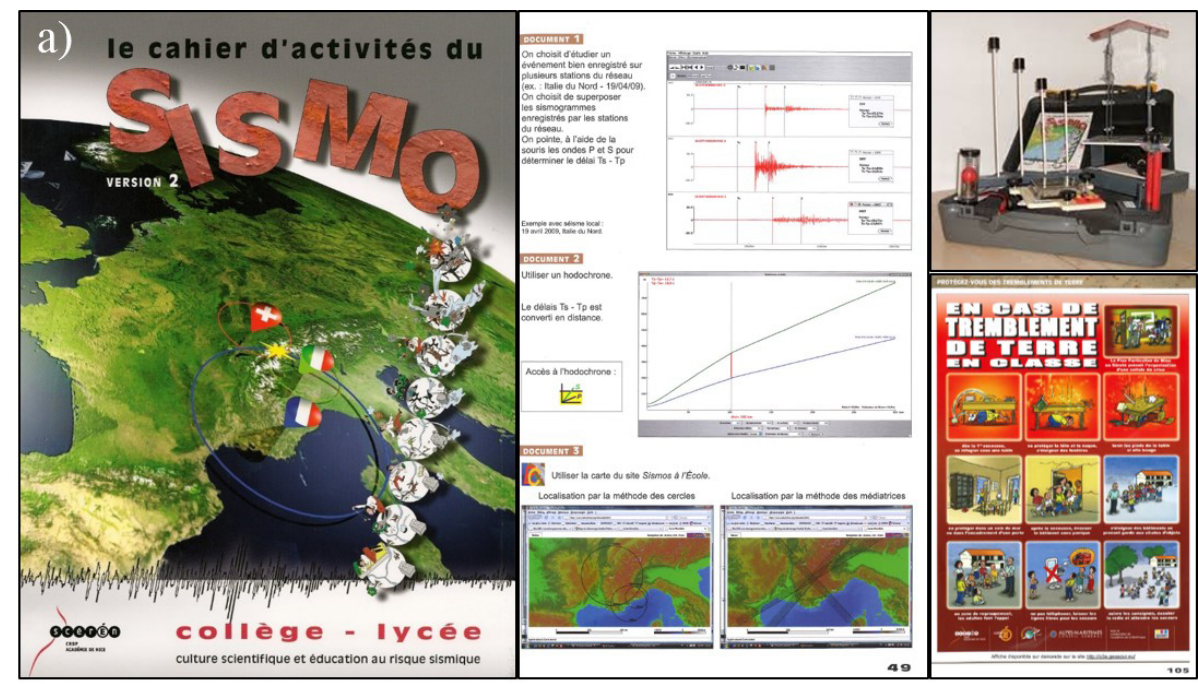

b)

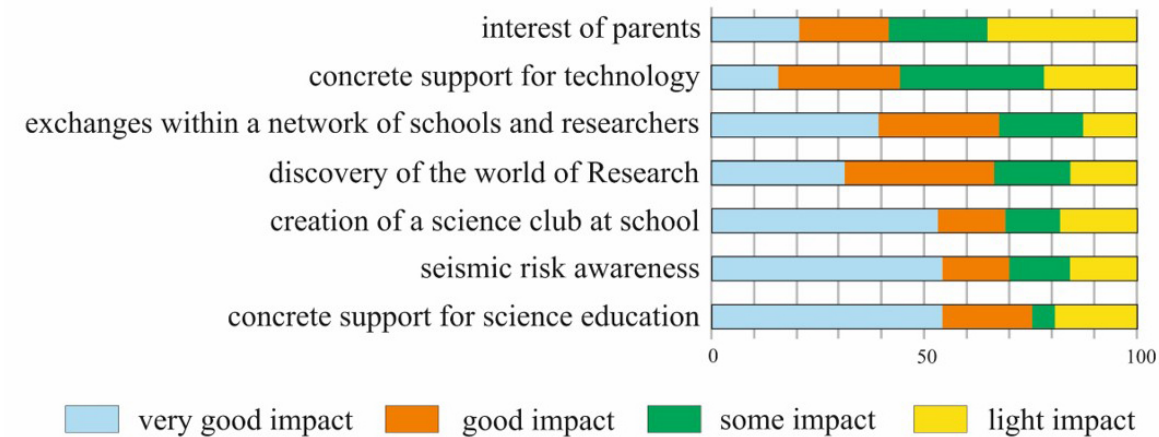

Figure 2. Pedagogical resources produced by the French educational network. (a) The seismo exercise book and the seismo box used to illustrate many aspects of the seismic phenomenon. (b) Focus on teachers' answers to the survey. In this case, the graph shows the impact of the installation of a seismometer at a school relative to different considerations.

- communicate in scientifically appropriate language, i.e., oral, written, graphical, and numerical.

The installation of seismometers at schools in different areas of Europe and abroad has given schools the necessary impetus to use a scientific approach for the improved development of activities concerning the knowledge of hazard, the realtime manipulation of information and scientific databases, and a better understanding of matters related to risk and territorial management (Courboulex et al., 2012). However, it remains important to evaluate how this has spread scientific culture and risk education to generations of students.

\section{The 25 years of the French seismology at school survey}

After 25 years, the time had come to make an overview of the teachers' vision of the impact of this network on their teaching and on student training. A survey was conducted in November 2019 among all teachers who have participated in the various actions of the program since it began. Note that these teachers are all teachers who are, or who were, the school reference person for the seismometer installed at one of the 105 schools in the network. Several of them are (or were) in charge of teacher training sessions in France and abroad. The number of responses may seem small, but their answers reflect the feelings of many more people. Collecting all feelings, reflections, and suggestions accumulated within the different special events carried out by the network should provide critical information for the future evolution of the educational network. Questions were listed to quantify the impact of the program on their teaching and on the awareness of science culture and risk education among students. The results presented in Fig. 2 are based on the responses of the $73 \%$ of the teams that have sent feedback, i.e., a total of 250 teachers. In France, Earth science is traditionally taught by biology and geology teachers. They provided the major contribution ( $85 \%$ of the answers) to the survey (compared with the contribution of only $15 \%$ of physics teachers). Half of them are teachers who have participated in an 
educational seismology program for more than 6 years. They consist in equal numbers of middle and high school teachers. A total of $80 \%$ of them (200 teachers) have participated in at least one of the training seminars on seismology and seismic risk described above. The main objective of the survey concerns the pedagogical value of installing a seismometer at a school. What is the greatest contribution of such instrument in a classroom? The interests are listed in descending order. The program has proven to be a facilitator for the following:

- practical support for science education (75.3\%)

- seismic risk awareness $(70.1 \%)$

- creation of a science club $(68.8 \%)$

- discovery of the world of research $(66.3 \%)$

- exchanges within a network of schools and researchers $(65.6 \%)$

- practical support for technology $(58.5 \%)$

- stimulation of the interest of parents $(45.5 \%)$.

The survey confirms that a seismometer installed at schools is an essential educational element for the majority of teachers. From teacher feedback, we also note that, through this sensor installed at the school, most of the students acquired skills to become ambassadors for seismic risk. Indeed, teachers mentioned that many students were invited to participate in scientific events in order to present their work. It can be considered that at least 20000 students have been able to participate in and benefit from the educational seismology program in France. Many of them are adults today, some of them have chosen a scientific career, but all are citizens who have been made aware of seismic risk by studying seismic phenomenon through the analysis of seismic data provided by educational and research seismometers.

\section{Conclusion}

All teachers agree on the fact that the presence of a seismometer at school is of great importance for the fulfillment of the main objectives of scientific culture and seismic risk education. Many other seismological networks for educational purposes have also emerged in Europe and around the world. Such educational programs have shown a positive impact among students (Zollo et al., 2014). Educational seismological networks also draw their strength from the interaction between teachers and researchers, which has occurred under various circumstances. If citizen science and educational seismology occupy such a prominent place in society today, it is because they ask for citizen commitment on important issues such as the prevention of seismic risk and, more generally, of natural risks. Schools play a central role when addressing a young public. The place of scientific research is also essential for better mitigation of natural hazards and for better understanding of the anthropogenic impact on environmental systems. Therefore, through this long-standing educational program with the driving motivation of building a seismic network across different educational communities in Europe, we must definitely focus on prevention through education. Educational seismology networks do more because they encourage students to adopt a scientific approach based on observation and measurement, enabling them to understand the causes of earthquakes, the internal dynamics of the globe - and to learn how the systems behave.

Similar programs can be developed in other countries if the education system in those countries is taken into account. However, one of the strongest elements for success is the training of educators, who are a key ingredient of the program. This training has followed teachers throughout the last few years. Indeed, any new educational project must support teachers by ensuring that they improve their scientific skills, specifically in Earth sciences. In order to achieve this goal, bringing teachers closer to researchers in a reciprocal interaction is important. Other key elements are the use of friendly, usable technical tools for manipulating scientific data and teaching resources, including learning aspects and assessment items. The way these features are developed is country dependent. Over the years, the French program has taken care to develop these activities (training courses, seminars, and conferences) for the various users, such as students, teachers, and researchers.

Thus, teaching seismology using real, recent data from online sensors gives a lot of satisfaction to students and teachers alike. This experience with educational seismology has now enabled the University of Côte d'Azur to set up an educational observatory of the Mediterranean environment (EduMed). This observatory offers a data center for teaching topics beyond seismology. Thus, using a similar educational approach, students and teachers have access to hydrogeological data with a range of diversity (river characteristics and karstic cave distribution). Meteorological data (rain, wind, and temperature) are another set of physical data to be analyzed and understood. Data from buoys at sea provide crucial data for the oceanic realm.

Over its first 3 years of operation, the access to various quantitative physical data related to the environment has allowed students to investigate different environmental subjects with the help of teachers in different disciplines who have different teaching expertise and interests. This extended program has broadened student skills, their education of natural risks, and their awareness of their natural and societal environments.

Finally, the challenge of educational seismology is the improved training of our students in Earth sciences so that they have a better understanding of how science is constructed and how it progresses. Undoubtedly, trained citizens are better equipped to face their future with a strengthened science- 
citizen link, and scientific vocations are the rewards of such innovative and attractive training.

Data availability. The book Le Cahier d'activités du SISMO, version 2 (Berenguer et al., 2009), funded by the Alcotra Program (European Union), was developed in 2009 and published by the school district of Nice (France). A digital version is available at http://namazu.unice.fr/EDUMEDOBS/seismo/ seismobook-version2.zip (last access: 6 December 2020, Berenguer et al., 2009). SeisGram $2 \mathrm{~K}$ and EduCarte (developed by Anthony Lomax and Jean-Luc Berenguer) software is downloadable from http://edumed.unice.fr/fr/contents/news/tools-lab/ SeisGram2K (last access: 6 December 2020, Lomax, 2000, https://doi.org/10.1785/gssrl.71.5.589) and http://edumed.unice.fr/ fr/contents/news/tools-lab/EduCarte (last access: 6 December 2020, Lomax and Michelini, 2009, https://doi.org/10.1111/j.1365246X.2008.03974.x).

The professional seismometers deployed during the initial, regional, and national phases were the SAGE station, with a three-component velocimeter (Noemax 20s). During the national phase, Güralp CMG-6TD devices were also deployed, such as the educational Vibrato station (https://www.staneo. fr/vibrato.php, last access: 6 December 2020, Berenguer et al., 2013). This device and the TC1 seismometer (Van Wijk et al., 2013, https://doi.org/10.1119/1.4830072) are currently deployed (EduMed-Obs phase).

Author contributions. JLB and JV conceived the idea of the seismological educational network. JLB, JV, and JB wrote the paper. FC, FM, and FJ read the paper and provided comments and corrections for improvements. JB composed all the figures in the paper.

Competing interests. The authors declare that they have no conflict of interest.

Acknowledgements. We are especially grateful to Guust Nolet and the reviewers for the comments and suggestions that helped us to greatly improve this paper. The educational network and activities presented in this paper have been supported from the beginning by the French Ministry of Education. We warmly thank all the teachers and researchers who have contributed, during these last 25 years, to the success of this educational network.

Financial support. This research has been supported by the French Ministry of Education. It has also been supported and funded by the French Ministerial "Sciences à l'École" project, the European NERA (Network of European Research Infrastructures for Earthquake Risk Assessment and Mitigation) and SERA (Seismology and Earthquake Engineering Research Infrastructure Alliance for Europe; grant no. 730900) research projects, the French Géoazur laboratory, and the Université Côte d'Azur, through the EduMed Observatory, since 2018 (UCA-JEDI "Investments in the Future" project (grant no. ANR-15-IDEX-01)).
Review statement. This paper was edited by Mirjam Sophia Glessmer and reviewed by Chris King and Denise Balmer.

\section{References}

Berenguer, J.-L., Pascucci, F., and Ferry, H.: Le cahier d'activités du SISMO, Version 2, edited by: CRDP (Centre Régional de Documentation Pédagogique), Scéren Nice, France, available at: http://namazu.unice.fr/EDUMEDOBS/ seismo/seismobook-version2.zip (last access: 6 December 2020), 2009 (in French).

Berenguer, J.-L., Courboulex, F., Tocheport, A., and Bouin, M.-P.: Tuned in to the Earth ... from the school EduSismo: the French educational seismological network, B. Soc. Geol. Fr., 184, 183-187, https://doi.org/10.2113/gssgfbull.184.1-2.183, available at: https://www.staneo.fr/vibrato.php (last access: 6 December 2020), 2013.

Bigot-Cormier, F. and Berenguer, J.-L.: How students Can Experience Science and Become Researchers: Tracking MERMAID Floats in the Oceans, Seismol. Res. Lett., 88, 416-420, https://doi.org/10.1785/0220160121, 2017.

Courboulex, F., Berenguer, J. L., Tocheport, A., Bouin, M. P., Calais, E., Esnault, Y., and Virieux, J.: SISMOS à l'Ecole: A Worldwide Network of Realtime Seismometers in Schools, Seismol. Res. Lett., 83, 870-873, https://doi.org/10.1785/0220110139, September/October 2012.

Lomax, A.: The Orfeus Java Workshop: Distributed Computing in Earthquake Seismology, Seismol. Res. Lett., 71, 589592, https://doi.org/10.1785/gssrl.71.5.589, available at: http: //edumed.unice.fr/fr/contents/news/tools-lab/SeisGram2K (last access: 6 December 2020), 2000.

Lomax, A. and Michelini, A.: $M_{w p d}$ : A duration-amplitude procedure for rapid determination of earthquake magnitude and tsunamigenic potential from P waveforms, Geophys. J. Int., 176, 200-214, https://doi.org/10.1111/j.1365-246X.2008.03974.x, available at: http://edumed.unice.fr/fr/contents/news/tools-lab/ EduCarte (last access: 6 December 2020), 2009.

Steinberg, D.-J., Phinney, R. A., and Nolet, A. M.: The Princeton Earth Physics Project presents: Seismometers-Telescopes for the Earth's Interior, American Astronomical Society, 196th AAS Meeting, id.24.04, Bulletin of the American Astronomical Society, 32, p. 707, available at: https://ui.adsabs.harvard.edu/abs/ 2000AAS...196.2404S (last access: 6 December 2020), 2000.

Van Wijk, K., Channel, T., Viskupic, K., and Smith, M. L.: Teaching Geophysics with a Vertical-Component Seismometer, Phys Teach., 51, 552-554, https://doi.org/10.1119/1.4830072, 2013.

Virieux, J.: Educational Seismological project: EDUSEIS, Seismol. Res. Lett., 71, 530-535, https://doi.org/10.1785/gssrl.71.5.530, 2000.

Zollo, A., Bobbio, A., Berenguer, J. L., Courboulex, F., Denton, P., Festa, G., Sauron, A., Solarino, S., Haslinger, F., and Giardini, D.: The European Experience of Educational Seismology, in: Geoscience Research and Outreach, edited by: Tong, V., Innovations in Science Education and Technology, Springer, Dordrecht, 21, 145-170, https://doi.org/10.1007/978-94-007-69434_10, 2014. 